\title{
Abciximab for thrombolysis during intracranial aneurysm coiling
}

\author{
Jan Gralla • Adam T. M. Rennie • Rufus A. Corkill • \\ Shivendra T. Lalloo • Andrew Molyneux • \\ James V. Byrne • Wilhem Kuker
}

Received: 2 May 2008 / Accepted: 1 September 2008 / Published online: 20 September 2008

(C) Springer-Verlag 2008

\begin{abstract}
Introduction Thrombotic events are a common and severe complication of endovascular aneurysm treatment with significant impact on patients' outcome. This study evaluates risk factors for thrombus formation and assesses the efficacy and safety of abciximab for clot dissolution.

Materials and methods All patients treated with abciximab during (41 patients) or shortly after (22 patients) intracranial aneurysm coil embolisation were retrieved from the institutional database (2000 to 2007, 1,250 patients). Sixty-three patients (mean age, 55.3 years, \pm 12.8 ) had received either intra-arterial or intravenous abciximab. Risk factors for clot formation were assessed and the angiographic and clinical outcome evaluated. Results No aneurysm rupture occurred during or after abciximab application. The intra-procedural rate of total recanalisation was $68.3 \%$. Thromboembolic complications were frequently found in aneurysms of the Acom complex and of the basilar artery, whilst internal carotid artery aneurysms were underrepresented. Two patients died of treatment-related intracranial haemorrhages into preexisting cerebral infarcts. Two patients developed a symptomatic groin haematoma. Conclusions Abciximab is efficacious and safe for thrombolysis during and after endovascular intracranial aneurysm treatment in the absence of preexisting ischaemic stroke.
\end{abstract}

J. Gralla $(\bowtie) \cdot$ A. T. M. Rennie $\cdot$ R. A. Corkill $\cdot$ S. T. Lalloo

A. Molyneux $\cdot$ J. V. Byrne $\cdot$ W. Kuker

Department of Neuroradiology,

West Wing, John Radcliffe Hospital,

Headley Way, Headington,

Oxford OX3 9DU, UK

e-mail: jan.gralla@insel.ch

J. Gralla

Department of Neuroradiology,

Inselspital-University of Bern,

Bern, Switzerland
Keywords Abciximab - Aneurysm · Endovascular treatment $\cdot$ Thromboembolic complication

\section{Introduction}

Thromboembolic events during or immediately after the endovascular treatment of intracranial aneurysms occur in $3-6 \%$ of procedures [1-5]. Heparin is used in most centres during aneurysm treatment to prevent thromboembolic events, either as a bolus or in the saline flushes of the catheters $[1,6,7]$. Furthermore, many centres apply aspirin and/or clopidogrel before or during intervention to reduce thromboembolic events.

However, permanent neurological disability caused by procedure-related ischaemic events still occurs in $1.7-5 \%$ of the patients $[1,8]$.

The identification of risk factors for thrombus formation may facilitate the adjustment of peri-interventional anticoagulation to reduce embolic events. A safe and efficacious treatment of thrombotic vessel occlusion may also improve patients' outcome. Various approaches have been advocated in the past including mechanical disruption of the thrombus [9] and application of fibrinolytic drugs [10]. Some studies have investigated the efficiency and safety of the glycoprotein IIb/IIIa antagonists Tirofiban or Eptifibatide [11-13]. Recently, several case reports [14-16] and smaller clinical studies $[1,9,17,18]$ have suggested good recanalisation rates following the use of the glycoprotein IIb/IIIa antagonist abciximab. However, the application route, dosage and timing vary (Table 1).

The risk of aneurysm re-bleed is of utmost concern if abciximab is used to treat clot formation in acutely ruptured aneurysms. This study evaluates risk factors for procedural clot formation during the endovascular treatment of 
Table 1 Studies on abciximab during endovascular aneurysm treatment.

\begin{tabular}{lcll}
\hline Study & $\begin{array}{l}\text { No. of } \\
\text { patients }\end{array}$ & $\begin{array}{l}\text { Route of } \\
\text { administration }\end{array}$ & $\begin{array}{l}\text { Intracranial } \\
\text { haemorrhagic } \\
\text { complications }\end{array}$ \\
\hline Mounayer et al. 2003 [1] & 13 & ia & - \\
Song et al. 2004 [17] & 7 & ia & {$[1]^{\mathrm{a}}$} \\
Aviv et al. 2005 [18] & 13 & iv & - \\
Velat et al. ${ }^{\text {b } 2006[9]}$ & 29 & ia + iv & 3 \\
Present study & 63 & ia/iv & 2 \\
\hline
\end{tabular}

${ }^{a}$ Leakage of contrast material, no symptomatic ICH

${ }^{\mathrm{b}}$ Study included different intracranial endovascular procedures

cerebral aneurysms and assesses the safety of abciximab application in 63 patients.

\section{Materials and methods}

Patients who underwent endovascular aneurysm treatment and received abciximab in our department were retrieved from a database of 1,250 patients. We found 63 cases which represented the sample of our study, and all following relative values are derived from these. In addition, the medical records and imaging studies were reviewed.

Our centre has a neurosurgical service; the decision for the endovascular or open surgical approach is based on a consensus between neurosurgeon and interventionalist.

The indication for treatment of an unruptured aneurysm was based on individual decisions, either based on the size and location and, therefore, the rupture risk of the aneurysm or on the neurological symptoms if present.

All procedures were performed by an experienced neuroradiologist under general anaesthesia using the spectrum of standard devices and procedures.

In most centres, anticoagulation before and during intervention and especially treatment of thromboembolic complications is not established by the application of a single drug.

In our department, a heparin bolus (5,000 IU) was routinely administered during intervention, and the catheters were flushed continuously with heparinised sodium chloride solution $(5 \mathrm{IU} / \mathrm{ml})$. The activated clotting time was monitored (Hemochrom Response, ITC, New York, USA) in an attempt to achieve doubled baseline levels during the procedure. In five patients, the initial bolus of heparin did not achieve double baseline levels, and an additional bolus of 2,000 IU heparin was given. Seven patients received pre-medication with aspirin; in ten cases, aspirin was given during intervention, in seven cases in combination with clopidogrel.
All patients received abciximab (ReoPro, Eli Lilly, Indianapolis, USA) either as a slow intra-arterial or intravenous hand injection (intra-procedural) or infusion (post-procedural). Two patients received an additional dose of $5 \mathrm{mg}$ recombinant tissue plasminogen activator (rt-PA).

For further analysis, the patients were divided as follows: The first group includes patients with thromboembolic complications during the procedure. The thrombus formation was documented angiographically and treated immediately. Abciximab was injected either intra-arterially via the microcatheter/guide catheter or intravenously through a peripheral line. If the thromboembolic event occurred either adjacent or downstream to the aneurysm, the success of the abciximab application was demonstrated angiographically and rated as complete, partial or lacking. In one patient, abciximab was given for thrombus formation in the basilar artery before the treatment of a ruptured posterior cerebral artery aneurysm. In all other patients, at least one coil was in place at the time abciximab was administered.

The second group comprised patients without thrombus formation during the intervention that developed focal neurological deficits suggestive of thromboembolic events from the aneurysm within $12 \mathrm{~h}$. After intracranial haemorrhage (ICH) was excluded by computed tomography (CT), these were treated with a 20- to 30-min infusion of abciximab intravenously. The recanalisation was not documented angiographically. This protocol has been has been abandoned and the authors do not advocate this protocol.

The size of the aneurysm neck was measured on the 3D angiogram and/or the CT angiography (CTA) and classified as small (neck diameter $\leq 4 \mathrm{~mm}$ ) or broad $(>4 \mathrm{~mm}$ ). This value is proportional to the neck-vessel interface and can therefore be considered as a measure for the coil-blood interface.

Angiographic recanalisation was graded into: total, subtotal and unchanged thrombus formation. The clinical outcome was assessed at discharge according to the modified Rankin scale (mRS). In some cases, additional devices (e.g. stent, balloon remodelling) were used during aneurysm treatment procedures. The risk of thromboembolic complications in these patients was recorded.

Student's $t$ test and odds ratio and 95\% confidential interval (95\% CI) were used for between-group analysis. MannWhitney test was applied for comparison of recanalisation grading.

\section{Results}

In 63 patients ( $5 \%$ of all 1,250 records), a thromboembolic complication occurred which was serious enough to warrant thrombolytic treatment with abciximab (39 women 
and 24 men, mean age 55.3 years, \pm 12.8 ). The initial mean World Federation of Neurological Surgeons score was 1.6 (range $0-5, \pm 1.2)$. In 51 patients $(81 \%)$, the aneurysm had ruptured within the last 28 days. The median interval between ictus and treatment was 5 days (range 0-28, \pm 4.8 ). Ten patients $(16 \%)$ were treated for an unruptured aneurysm (seven incidental, three coincidental). Two further patients (3\%) received delayed aneurysm treatment ( $>6$ months) after a previous subarachnoid haemorrhage (SAH) and were considered as unruptured. The mean dose of abciximab was $12.7 \mathrm{mg}$ (range $2-30, \pm 5.6$ ).

The localisation of aneurysms showed the following distribution: The Acom complex ( $\mathrm{A}_{1}, \mathrm{~A}_{2}$ and Acom) was affected in 27 patients $(42 \%)$, the middle cerebral artery in 12 patients $(19 \%)$ and the basilar artery in 11 patients $(17.5 \%)$. Rare locations included the Pcom (four patients, $6.3 \%$ ), the pericallosal artery (three patients, $4.8 \%$ ), the internal carotid artery (ICA; three patients, $4.8 \%$ ), the Pica (two patients, 3.2\%) and the posterior cerebral artery (one patient, $2.6 \%$ ). In 40 aneurysms (63.5\%), the neck was $<4 \mathrm{~mm}$ in diameter, in 23 aneurysm (36.5\%) $4 \mathrm{~mm}$ or larger.

Coiling was assisted by additional devices in 14 patients (17.5\%). These were 11 balloon-remodelling procedures, two Trispan applications and one intravascular stent placement. An ICH was not found in the small subgroup of patients treated with additional devices.

Of the 41 patients (mean age 54.9 years, \pm 13.4 ) with intraprocedural clot formation, 27 patients received abciximab intra-arterially and 12 intravenously. Two patients received it both intra-arterially and intravenously. A mean dose of $13.5 \mathrm{mg}$ abciximab was given (range $2-30, \pm 13.5$ ). In 35 patients $(85.4 \%)$, the thromboembolic events were adjacent to the aneurysm or downstream. In six patients $(14.6 \%)$, other territories were involved.

The abciximab administration completely resolved the obstruction in 28 of 41 patients $(68.3 \%$, case illustration, Fig. 1). In eight of 41 patients $(19.5 \%)$, the application led to a subtotal recanalisation, and in five of 41 patients (12.2\%), the thrombus remained unchanged (Table 2). No significant difference was found in the recanalisation rates between intra-procedural IV and IA application. The mean $\mathrm{mRS}$ score at discharge was 1.4.

In the group of patients with intraprocedural administration of abciximab, eight patients were additionally treated with anti-platelet medication. No significant differences in recanalisation rate were found for this small subgroup.

Twenty-two patients (mean age 56.1 years, \pm 11.9 ) received abciximab during the immediate post-interventional course (mean dose $11.3 \mathrm{mg}$, range $7.5-20, \pm 3.6 \mathrm{mg}$ ). The two groups did not differ significantly in the mean dose of abciximab $(P<0.005)$. Fifteen of the 22 patients $(68 \%)$ improved significantly after delayed i.v. administration of abciximab. In seven patients $(32 \%)$, the neurological deficit remained unchanged. The mean mRS score at discharge was 1.9.

Two patients (3.2\%) suffered a fatal ICH after the endovascular procedure, one after intra-procedural abciximab and the other after post-procedural application of abciximab. The first of these, a 48-year-old female patient, had been treated with balloon remodelling for a coincidental unruptured basilar artery termination aneurysm. Two hours after uncomplicated coiling, the patient developed severe left-sided hemiparesis. After a haemorrhage had been excluded by CT, the patient received $20 \mathrm{mg}$ of abciximab intravenously. The
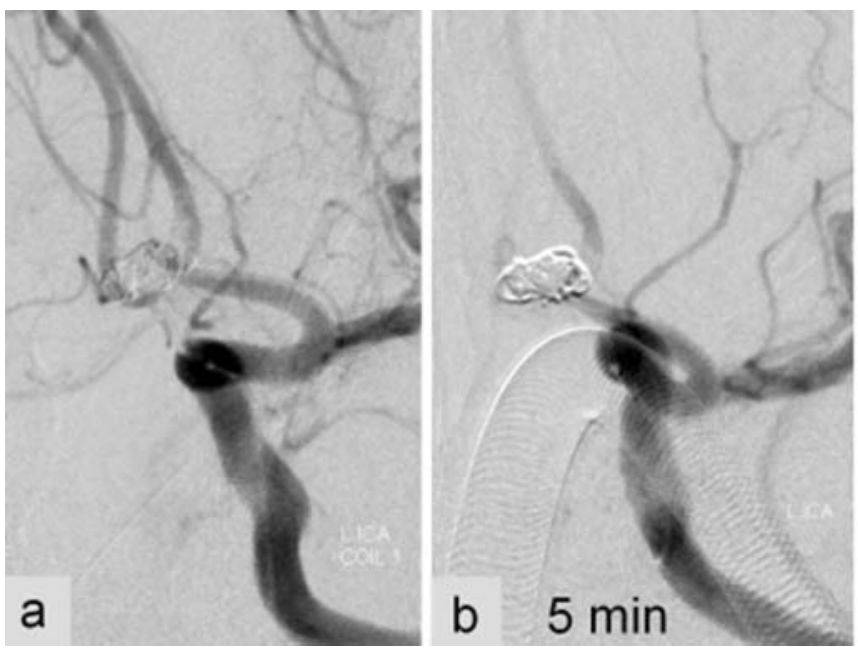

Fig. 1 Successful recanalisation using abciximab. After deployment of the second coil during endovascular treatment of an Acom aneurysm, the angiogram reveals thrombus formation in the adjacent $\mathrm{A}_{2}$ segment of the left ACA (a). Within $5 \mathrm{~min}(\mathbf{b})$, the thrombus

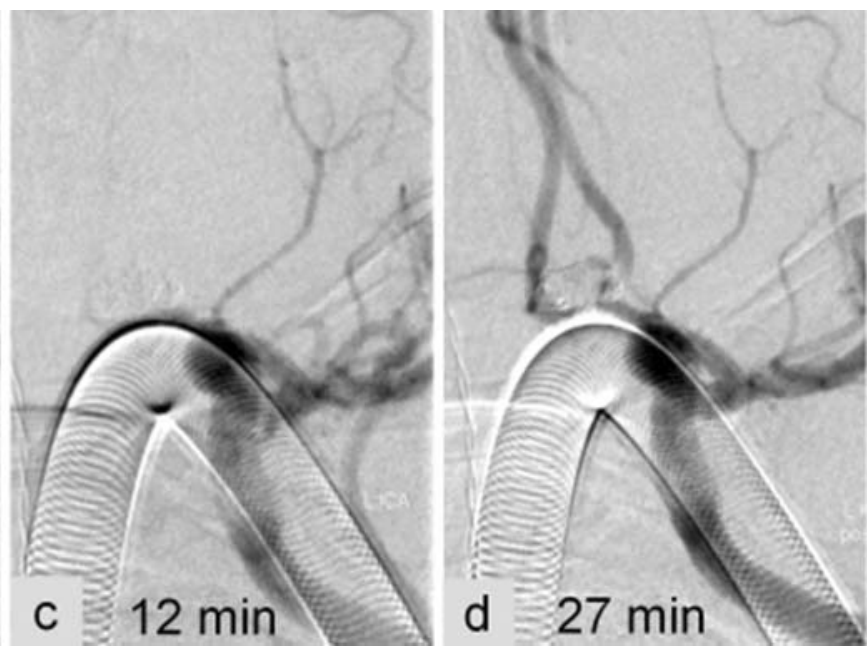

propagates into both $\mathrm{A}_{2}$ segments (c) and leads to a total occlusion. The immediate application of intra-arterial thrombolysis achieves a fast recanalisation (d) and prevents post-interventional neurological deficits in this 62-year-old female patient 
Table 2 Recanalisation results.

\begin{tabular}{llllll}
\hline Route of administration & $\begin{array}{l}\text { No. of } \\
\text { patients }\end{array}$ & Mean age (year) & $\begin{array}{l}\text { Mean dose in } \\
\text { mg (range) }\end{array}$ & Recanalisation & No. of ICH \\
\hline Intraprocedural & 41 & 54.9 & $13.5(2-30)$ & & 1 \\
& & & $\begin{array}{l}\text { Complete, } 68.3 \% \\
\text { Subtotal, } 19.5 \%\end{array}$ & \\
No., 12.5\% & & 1 \\
Postprocedural & 22 & & $11.3(7.5-20)$ & & 1 \\
\hline
\end{tabular}

follow-up CT $4 \mathrm{~h}$ later demonstrated a large right-hemispheric haemorrhage including thalamus and basal ganglia.

The second fatal bleed occurred into the cerebellum of a 59-year-old patient $6 \mathrm{~h}$ after coiling of a Pica aneurysm (Fig. 2) and the administration of $3 \mathrm{mg}$ abciximab.

Retrospective analysis revealed that the haemorrhages had occurred into infarcted brain tissue and were not caused by re-rupture of the aneurysm.

Two patients $(3.2 \%)$ developed a large and symptomatic groin haematoma, which in one patient developed into a false aneurysm. Other haemorrhagic complications such as gastrointestinal or retroperitoneal complications were not encountered.

\section{Discussion}

Thrombus formation is the most common complication during endovascular aneurysm treatment and may significantly impact on the clinical outcome.

The identification of risk factors for thrombus formation with the consequent adjustment of peri-interventional anticoagulation and the safe and efficient treatment of thrombotic events may both improve patients' outcome.
This study evaluates predisposing factors for clot formation and assesses the safety and efficacy of abciximab for its treatment.

Predisposing factors for thromboembolic complications

In our patient group, the most frequent site of clot formation was the treated aneurysm or downstream to the aneurysm (85.4\%), and not the catheter system. Little data are available on the risk factors for thrombus formation at the blood-coil interface [7].

In our study, $36.5 \%$ of the thromboembolic complications occurred during the treatment of wide-necked aneurysms, whereas the majority $(63.5 \%)$ were encountered during the embolisation of aneurysms with a neck diameter $\leq 4 \mathrm{~mm}$. Hence, neck size does not appear to be the sole determining factor of thrombus formation. Other factors contributing to thrombosis may include manipulation within the aneurysm and blood flow alteration by catheters or balloons. The propensity of additional devices (e.g. stent, balloon) to induce thromboembolic complications is still under debate. Although some previous studies reported a higher incidence of thromboembolic complications [4, 19] if these were used, we did not find a significant difference. These results are in
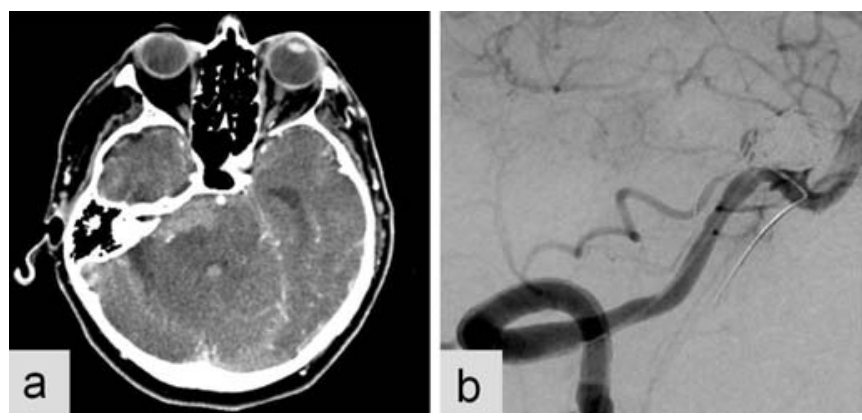

Fig. 2 Fatal intracranial haemorrhage into a preexisting ischaemic area. The patient was treated with a balloon-assisted coiling of a widenecked Pica aneurysm 5 days after SAH. During intervention, thrombus formation is noted in the proximal Pica adjacent to the aneurysm (b). In addition to mechanical disruption attempts, the thrombus formation is treated locally during intervention with $3 \mathrm{mg}$ of abciximab through the microcatheter resulting in thrombus resolution
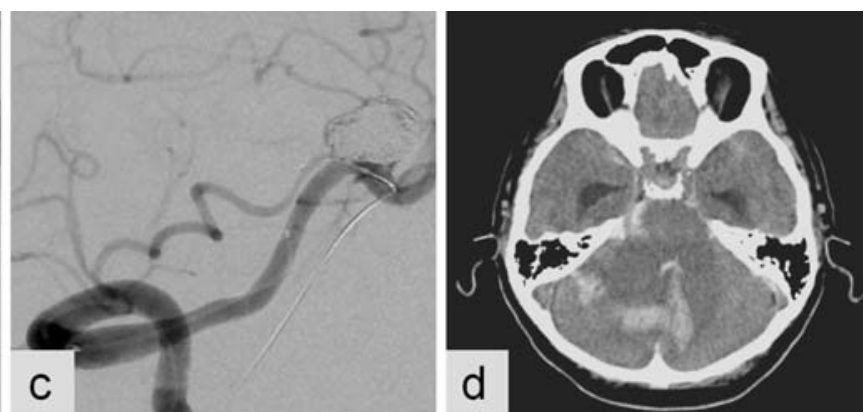

(c). Six hours later, the patient deteriorates, and a CT scan demonstrates an intra-cerebellar haematoma (d). The retrospective evaluation of the pre-interventional CTA reveals a hypodense region in the right cerebellum (a), presumably a preexisting subacute ischaemic lesion. No further SAH or signs of a re-rupture of the aneurysm were found 
line with the findings of Layton at al. [20]. The application of additional devices did not increase the risk of ICH.

Among all our patients, a predisposing factor for clot formation seems to be aneurysm location. Aneurysms of the Acom complex (42\%) and the basilar artery (17.5\%) led most frequently to thrombus formation requiring treatment. These numbers are in excess of the natural distribution of aneurysms among our patients. Reviewing the data of previous studies, Aviv et al. [18] reported five Acom aneurysms (38.5\%) in a series of 13 . In another publication, Velat et al. [9] found clot formation in ten basilar artery aneurysms (38.5\%) among a total of 26 . The number of thromboembolic complications during the treatment of ICA lesions is surprisingly low (4.8\%).

The high rate of thrombus formation in the treatment of aneurysms of the Acom complex and the basilar artery may be due to slow or turbulent flow, further impaired by endovascular equipment.

The female predominance in the present study ( $62 \%$ female patients) may not represent a sex-related predisposition for thromboembolic complications, as this could solely reflect the female predominance of aneurysms in general [21].

\section{Efficacy and safety of abciximab}

In most centres, anticoagulation before and during intervention and especially treatment of thromboembolic complications is not established by the application of a single drug. In our study, all patients received a pre-interventional bolus of heparin, a total of 17 patients received aspirin, and seven patients additionally received clopidogrel. In two cases, an additional dose of $5 \mathrm{mg}$ rt-PA was applied. Therefore, as a limitation of the study, the clinical setting does not allow distinguishing between the effect of abciximab alone and the effect of the combination of drugs.

The long-term outcome in patients after SAH mainly depends on haemorrhage-related complications. Hence, the impact of intra-procedural thrombolysis of patient outcome is difficult to quantify in small studies. Our series, which is the largest study so far, confirms the results of previous studies $[9,17]$.

Using angiographic and clinical criteria, we consider abciximab as an effective drug for the treatment of thrombotic complications during and after aneurysm coiling with complete recanalisation or clinical improvement in $68 \%$ of the patients.

Table 1 summarises previous reports on abciximab. There is no consensus on the most effective application route for the drug in literature nor did we see any difference between intra-arterial and intravenous delivery. Although intra-arterial injection yields higher drug concentrations at the thrombus, this has not been shown to result in better clinical efficiency. High systemic activity after intravenous injection may be sufficient to achieve the same effect. Abciximab blocks approximately $80 \%$ of all GPIIb/IIIa receptors and disables platelet function for $48 \mathrm{~h}[22,23]$. The delayed administration of abciximab in patients with neurological symptoms after the intervention proved to be less effective. As previously mentioned, the protocol of delayed administration of abciximab without prior angiographic evaluation has been abandoned. CTA or catheter angiograms are widely available now to investigate the underlying cause of novel neurological deficits in the post-interventional course (e.g. vasospasm).

The application of a thrombolytic drug during the treatment of an acutely ruptured aneurysm may resolve the thrombus but bears the risk of a fatal haemorrhage.

The interest focuses on the treatment strategy with the best risk-to-benefit ratio. Various drugs have been used and reported in small case series. Cronqvist et al. [10] reported a high re-rupture and ICH rate leading to a poor neurological outcome in patients treated with urokinase during aneurysm coiling. The focus has since shifted to antiplatelet drugs, as it emerges that procedural complications $[6,24]$ are often caused by platelet-rich thrombi.

First reports have suggested a good recanalisation rate for abciximab. This chimeric and monoclonal human murine antibody binds to the GPIIb/IIIa receptor. It inhibits platelet aggregation and platelet binding to fibrinogen and dissolves thrombi [25-27]. However, the effect of abciximab can only be antagonised by platelet substitution.

In the present study, none of the 51 ruptured and 12 unruptured aneurysms bled during or after the application of abciximab. Two patients suffered a fatal ICH, both into distant parts of the brain, probably into subacute infarcts.

The reasons for this selective effect of abciximab on clot formation are difficult to understand. One reason might be the changes in haemodynamics within the aneurysm due to the coil. Furthermore, the thrombus sealing the ruptured aneurysm may differ from the clot complicating the treatment, with the thrombus sealing the aneurysm having matured and stabilised to contain a high amount of fibrin. Therefore, abciximab may be less effective at destabilising this crucial clot component than a fibrinolytic drug-like urokinase.

Recent data indicate that the administration of abciximab in the treatment of patients' acute ischaemia increases the risk of symptomatic and fatal ICH [28]. The number of patients evaluated in our study is comparably low; however, we did not observe an increased rate of ICH in this hyperacute setting of ischaemic cerebral stoke. Haemorrhages occurred in patients with subacute ischaemic brain areas. The differences between the findings in acute stroke patients and patients with thromboembolic events during endovascular treatment might be explained by the time window between vessel occlusion and administration of abciximab. This time span during endovascular treatment is in the range of 
minutes compared to the treatment of acute stroke patients. The short ischaemic interval might be a possible explanation for the low rate of reperfusion injury and $\mathrm{ICH}$.

Two patients developed a symptomatic groin haematoma; one required interventional treatment. This is a wellestablished complication of abciximab reported in the interventional cardiology literature [29].

We can conclude that the application of abciximab for thrombotic complications of aneurysm treatment is effective and safe in the absence of subacute ischaemic stroke.

Conflict of interest statement We declare that we have no conflict of interest.

\section{References}

1. Mounayer C, Piotin M, Baldi S, Spelle L, Moret J (2003) Intraarterial administration of Abciximab for thromboembolic events occurring during aneurysm coil placement. AJNR Am J Neuroradiol 24(10):2039-2043

2. Eskridge JM, Song JK (1998) Endovascular embolization of 150 basilar tip aneurysms with Guglielmi detachable coils: results of the Food and Drug Administration Multicenter Clinical Trial. J Neurosurg 89(1):81-86

3. van Rooij WJ, Sluzewski M, Beute GN, Nijssen PC (2006) Procedural complications of coiling of ruptured intracranial aneurysms: incidence and risk factors in a consecutive series of 681 patients. AJNR Am J Neuroradiol 27(7):1498-1501

4. Henkes H, Fischer S, Weber W, Miloslavski E, Felber S, Brew S et al (2004) Endovascular coil occlusion of 1811 intracranial aneurysms: early angiographic and clinical results. Neurosurgery 54(2):268-280. doi:10.1227/01.NEU.0000103221.16671.F0

5. van Rooij WJ, Sluzewski M, Beute GN, Nijssen PC (2006) Procedural complications of coiling of ruptured intracranial aneurysms: incidence and risk factors in a consecutive series of 681 patients. AJNR Am J Neuroradiol 27(7):1498-1501

6. Grunwald IQ, Papanagiotou P, Politi M, Struffert T, Roth C, Reith W (2006) Endovascular treatment of unruptured intracranial aneurysms: occurrence of thromboembolic events. Neurosurgery 58(4):612-618. doi:10.1227/01.NEU.0000204101.00996.D9

7. Workman MJ, Cloft HJ, Tong FC, Dion JE, Jensen ME, Marx WF et al (2002) Thrombus formation at the neck of cerebral aneurysms during treatment with Guglielmi detachable coils. AJNR Am J Neuroradiol 23(9):1568-1576

8. Vinuela F, Duckwiler G, Mawad M (1997) Guglielmi detachable coil embolization of acute intracranial aneurysm: perioperative anatomical and clinical outcome in 403 patients. J Neurosurg 86 (3):475-482

9. Velat GJ, Burry MV, Eskioglu E, Dettorre RR, Firment CS, Mericle RA (2006) The use of abciximab in the treatment of acute cerebral thromboembolic events during neuroendovascular procedures. Surg Neurol 65(4):352-358 discussion. doi:10.1016/j. surneu.2005.08.024

10. Cronqvist M, Pierot L, Boulin A, Cognard C, Castaings L, Moret $\mathrm{J}$ (1998) Local intraarterial fibrinolysis of thromboemboli occurring during endovascular treatment of intracerebral aneurysm: a comparison of anatomic results and clinical outcome. AJNR Am J Neuroradiol 19(1):157-165

11. Bruening R, Mueller-Schunk S, Morhard D, Seelos KC, Brueckmann H, Schmid-Elsaesser R et al (2006) Intraprocedural thrombus formation during coil placement in ruptured intracranial aneurysms: treatment with systemic application of the glycoprotein IIb/IIIa antagonist tirofiban. AJNR Am J Neuroradiol 27 (6):1326-1331

12. Yi HJ, Gupta R, Jovin TG, Tayal A, Genevro J, Gologorsky Y et al (2006) Initial experience with the use of intravenous eptifibatide bolus during endovascular treatment of intracranial aneurysms. AJNR Am J Neuroradiol 27(9):1856-1860

13. Katsaridis V, Papagiannaki C, Skoulios N, Achoulias I, Peios D (2008) Local intra-arterial eptifibatide for intraoperative vessel thrombosis during aneurysm coiling. AJNR Am J Neuroradiol 29:1414-1417

14. Cloft HJ, Samuels OB, Tong FC, Dion JE (2001) Use of abciximab for mediation of thromboembolic complications of endovascular therapy. AJNR Am J Neuroradiol 22(9):1764-1767

15. Bendok BR, Padalino DJ, Levy EI, Qureshi AI, Guterman LR, Hopkins LN (2004) Intravenous abciximab for parent vessel thrombus during basilar apex aneurysm coil embolization: case report and literature review. Surg Neurol 62(4):304-311. doi:10.1016/j.surneu.2003.10.045

16. Ng PP, Phatouros CC, Khangure MS (2001) Use of glycoprotein IIb-IIIa inhibitor for a thromboembolic complication during Guglielmi detachable coil treatment of an acutely ruptured aneurysm. AJNR Am J Neuroradiol 22(9):1761-1763

17. Song JK, Niimi Y, Fernandez PM, Brisman JL, Buciuc R, Kupersmith MJ et al (2004) Thrombus formation during intracranial aneurysm coil placement: treatment with intra-arterial abciximab. AJNR Am J Neuroradiol 25(7):1147-1153

18. Aviv RI, O'Neill R, Patel MC, Colquhoun IR (2005) Abciximab in patients with ruptured intracranial aneurysms. AJNR Am J Neuroradiol 26(7):1744-1750

19. van Rooij WJ, Sluzewski M, Beute GN, Nijssen PC (2006) Procedural complications of coiling of ruptured intracranial aneurysms: incidence and risk factors in a consecutive series of 681 patients. AJNR Am J Neuroradiol 27(7):1498-1501

20. Layton KF, Cloft HJ, Gray LA, Lewis DA, Kallmes DF (2007) Balloon-assisted coiling of intracranial aneurysms: evaluation of local thrombus formation and symptomatic thromboembolic complications. AJNR Am J Neuroradiol 28(6):1172-1175. doi:10.3174/ajnr.A0490

21. Molyneux AJ, Kerr RS, Yu LM, Clarke M, Sneade M, Yarnold JA et al (2005) International subarachnoid aneurysm trial (ISAT) of neurosurgical clipping versus endovascular coiling in 2143 patients with ruptured intracranial aneurysms: a randomised comparison of effects on survival, dependency, seizures, rebleeding, subgroups, and aneurysm occlusion. Lancet 366(9488):809817. doi:10.1016/S0140-6736(05)67214-5

22. Mascelli MA, Lance ET, Damaraju L, Wagner CL, Weisman HF, Jordan RE (1998) Pharmacodynamic profile of short-term abciximab treatment demonstrates prolonged platelet inhibition with gradual recovery from GP IIb/IIIa receptor blockade. Circulation 97(17):1680-1688

23. Tcheng JE (1994) Dosing and administration of ReoPro (c7E3 Fab). J Invasive Cardiol 6(Suppl A):29A-33A

24. Ries T, Buhk JH, Kucinski T, Goebell E, Grzyska U, Zeumer H et al (2006) Intravenous administration of acetylsalicylic acid during endovascular treatment of cerebral aneurysms reduces the rate of thromboembolic events. Stroke 37(7):1816-1821. doi:10.1161/01. STR.0000226933.44962.a6

25. Coller BS, Peerschke EI, Scudder LE, Sullivan CA (1983) A murine monoclonal antibody that completely blocks the binding of fibrinogen to platelets produces a thrombasthenic-like state in normal platelets and binds to glycoproteins IIb and/or IIIa. J Clin Invest 72(1):325-338. doi:10.1172/JCI110973

26. Qureshi AI, Saad M, Zaidat OO, Suarez JI, Alexander MJ, Fareed M et al (2002) Intracerebral hemorrhages associated with neurointerven- 
tional procedures using a combination of antithrombotic agents including abciximab. Stroke 33(7):1916-1919. doi:10.1161/01. STR.0000019423.08947.43

27. Lee KY, Heo JH, Lee SI, Yoon PH (2001) Rescue treatment with abciximab in acute ischemic stroke. Neurology 56(11):1585-1587

28. Adams HP Jr, Effron MB, Torner J, Davalos A, Frayne J, Teal P et al (2008) Emergency administration of abciximab for treatment of patients with acute ischemic stroke: results of an international phase
III trial: abciximab in emergency treatment of stroke trial (AbESTTII). Stroke 39(1):87-99. doi:10.1161/STROKEAHA.106.476648

29. Blankenship JC, Hellkamp AS, Aguirre FV, Demko SL, Topol EJ, Califf RM (1998) Vascular access site complications after percutaneous coronary intervention with abciximab in the Evaluation of c7E3 for the Prevention of Ischemic Complications (EPIC) Trial. Am J Cardiol 81(1):36-40. doi:10.1016/S0002-9149 (97)00796-0 